\title{
Understanding Developmental Changes in the Stability and Flexibility of Spatial Categories Based on Object Relatedness
}

\author{
Alycia M. Hund and Emily K. Foster \\ Illinois State University
}

\begin{abstract}
Two experiments examined the flexibility and stability with which children and adults organize locations into categories on the basis of object relatedness. Seven-, 9-, and 11-year-olds and adults learned the locations of 20 objects belonging to 4 categories. Displacement patterns revealed that children and adults used object cues to organize the locations into groups. The organization remained the same following a 7-day delay for all 4 ages, demonstrating stability. Moreover, for 11-year-olds and adults, this organization shifted after a new pattern of object-location pairings was introduced. The pattern was less clear for the younger children, suggesting that flexibility increases across childhood. Discussion focuses on the dynamics of organization processes, particularly stability and flexibility, and the integration of objects and locations.
\end{abstract}

Keywords: spatial categorization, object location memory, flexibility, stability, object-location integration

Stability and flexibility are important hallmarks of cognition. Stability enables people to respond similarly when faced with similar situations or goals. For example, children need to know where the paint, brushes, and easels are kept to complete their painting projects. Because objects that are similar often are located in similar locations (e.g., in the art area), children can locate these objects quickly and effectively to complete their paintings day after day. Flexibility enables people to respond differently when faced with different situations or goals. For example, when completing an art project at school, children must be able to locate the supplies in their classroom. When completing an art project at home, however, they must locate the same items in a different environment. Clearly, the abilities to maintain organization over time (i.e., stability) and to shift to a new pattern of organization when faced with a new situation (i.e., flexibility) are important in everyday life. However, relatively little is known about the stability and flexibility with which children and adults organize and remember object locations. In particular, very little is known about how stability and flexibility processes interact over time. For example, might stability precede (and facilitate) flexibility, give way to flexibility, or emerge later as skills become refined? The goal of the present study was to examine how children and adults use object cues to organize locations into groups, thereby speci-

Alycia M. Hund and Emily K. Foster, Department of Psychology, Illinois State University.

This research was supported by a New Faculty Initiative Grant and a Pretenure Faculty Initiative Grant from Illinois State University awarded to Alycia M. Hund. We thank Jessica Schultz, Deah Partak, John Hoth, Jessica Buffington, and Sarah Brown for their help with data collection and coding. We also thank Thomas Metcalf School and all of the participants for their enthusiastic participation.

Correspondence concerning this article should be addressed to Alycia M. Hund, Department of Psychology, Illinois State University, Campus Box 4620, Normal, IL 61790-4620. E-mail: amhund@ilstu.edu fying the developmental emergence and balance of stability and flexibility in the integration of objects and locations.

\section{Category Stability and Flexibility}

Examining the stability and flexibility of category groupings enables researchers to understand the dynamics of categorization processes. For example, repeatedly assessing category formation in the same situation provides details regarding the emergence and maintenance of categories over time. Assessing category formation following different experiences provides information regarding the flexibility with which people form categories (Madole \& Oakes, 1999; Oakes \& Madole, 2000; Ross, 1996). In recent years, there has been a shift from viewing categories as static representations (e.g., Mandler, 1993; Mervis, 1985) toward viewing them as emergent processes (Barsalou, 1983, 2003; Hund \& Plumert, 2005; Jones \& Smith, 1993; Smith, 2000; Smith \& Heise, 1992; Smith \& Samuelson, 1997; Thelen \& Smith, 1994). According to this dynamic view, categories are created from multiple sources of information for the purpose of solving specific tasks. As such, stability results from the repeated combination of cues, leading to similarities in emergent categories over time. In contrast, flexibility results from the combination of different cues (e.g., linguistic context, object features) and from differences in the task at hand (e.g., naming, judging similarity, making generalizations). For example, in naming tasks, 3-year-old children demonstrate robust categorization based on shape in the context of a count noun (e.g., "This is a dax") when interacting with rigid objects (Landau, Smith, \& Jones, 1988). In similarity judgment tasks, however, 3-year-olds show nonsystematic categorization (Landau et al., 1988), whereas in property generalization tasks they categorize on the basis of shape when dealing with rigid objects and on the basis of material when dealing with objects made of deformable materials, such as beanbags and sponges (Samuelson \& Smith, 2000). According to dynamic systems views, the same processes that give rise to stability and flexibility in real-time categorization also lead 
to developmental changes in categorization (Jones \& Smith, 1993; Smith \& Samuelson, 1997; Thelen \& Smith, 1994). One way to test this claim is to specify how children and adults use available cues to form categories that meet current task demands, focusing particularly on the stability and flexibility of categorical organization.

What do we know about the emergence of flexibility and stability across development? Recently, Deák, Ray, and Pick (2004) examined the flexibility with which preschool children switched sorting rules in a task conceptually similar to the Wisconsin Card Sort Task (see Zelazo, Frye, \& Rapus, 1996, for a detailed description of the dimensional change card sorting task). Children were required to sort novel objects on the basis of concrete or abstract rules. Regardless of the difficulty of the rule or of reminders to think about the rules, 4- and 5-year-old children were able to shift to the new sorting rule, demonstrating flexibility. Three-yearolds were not as flexible as the older children but did show signs of rule-switching ability when asked to think about the new rule. These results suggest that flexibility emerges relatively early in development but that it increases during the preschool years. In a similar study, 3- to 6-year-old children were asked to infer category membership after learning novel words in sentence contexts that emphasized shape, material, or object parts (Deák, 2000). Four- to 6-year-olds used sentence context to infer word meaning, demonstrating flexibility. Three-year-olds had more difficulty using the sentence contexts differentially and tended to perseverate on particular features when making inferences, indicating that cognitive flexibility increases across early childhood (see also Blaye \& Bonthoux, 2001; Brace, Morton, \& Munakata, 2006; Bull \& Scerif, 2001; Diamond \& Doar, 1989; Kirkham, Cruess, \& Diamond, 2003; Yerys \& Munakata, 2006; Zelazo et al., 1996).

Additional findings have indicated that flexibility continues to increase across middle childhood and early adolescence, particularly in tasks involving spatial and semantic cues (Hund \& Plumert, 2005; Plumert, 1994). For example, recently, Hund and Plumert (2005) investigated the stability and flexibility with which 7-, 9-, and 11-year-old children and adults organized and remembered the locations of objects on the basis of spatiotemporal experience. Participants learned the locations of 20 unrelated objects in an open, square box. First, they watched the researcher place the objects on dots that marked the objects' locations. Then they were asked to replace the objects in the correct locations. Learning trials continued until the participants could correctly replace all 20 objects.

The objects and locations were identical across conditions; however, the pattern of spatiotemporal experience during learning differed across conditions. In the side condition, participants experienced the locations along the sides of the box together in time. In the quadrant condition, participants experienced the locations in the quadrants of the box together in time. During the test phase, participants attempted to replace the objects without the aid of the dots. Approximately 5 days later, participants again attempted to replace the objects without the aid of the location markers; this provided an index of stability. Then participants learned the locations of a new set of unrelated objects using the opposite pattern of spatiotemporal organization. Participants in all four age groups organized the locations on the basis of the pattern of spatiotemporal experience during the learning phase both during the first session and following a 5-day delay, demonstrating stability.
Adults were able to shift to a new pattern of organization following a change in the pattern of spatiotemporal contiguity during the second session, demonstrating flexibility. In contrast, 7- and 11year-old children only displayed flexibility when the new pattern of spatiotemporal organization was consistent with the perceptual task cues (e.g., the perceptual axes dividing the box into quadrants).

These findings suggest that flexibility depends on the integration of perceptual cues and remembered information in the task at hand. Moreover, they indicate that stability emerges relatively early during childhood but that flexibility increases across middle childhood (see also Kail, 1984; Plumert, 1994). The current investigation tested this latter proposal by examining the developmental emergence of stability and flexibility of spatial categories using another cue - object relatedness. As such, this investigation not only provides details about the dynamics of category processes, it sheds light on the complex interactions between object and location information more generally.

\section{Integrating Objects and Locations}

Object relatedness is an ideal cue for investigating category stability and flexibility because it is a powerful cue for creating spatial categories (e.g., Hund \& Plumert, 2003), and it is relatively easy to create different groupings of the same set of locations by manipulating which objects belong at nearby locations. Moreover, it is important both theoretically and practically to understand the complex interactions between objects and locations. Practically speaking, many everyday tasks require linking object and location information. For example, knowing that a workbook, pencil, and calculator are needed to complete a homework assignment is not beneficial unless these items can be located successfully. Conceptually, Shelton and McNamara (2004) asserted that understanding how people integrate object and location information is the critical challenge for contemporary researchers seeking to understand the dynamics of spatial cognition.

Traditional research has tended to focus on objects or locations in isolation, paying little attention to their important integrative functions. In many ways, this simplification was a result of knowing relatively little about underlying processes. Now, as researchers' knowledge about people's processing of objects and locations expands, the time is right to tackle the difficult and compelling issues surrounding how people think about objects and their locations as integrated wholes. Toward that end, researchers have begun to specify the complex ways object information and spatial information interact (Carlson-Radvansky, Covey, \& Lattanzi, 1999; Carlson-Radvansky \& Tang, 2000; Hirtle \& Kallman, 1988; Hirtle \& Mascolo, 1986; Hund \& Plumert, 2003; Postma, Kessels, \& van Asselen, 2004; Shelton \& McNamara, 2004; Uttal, Gregg, Tan, Chamberlin, \& Sines, 2001; see Ungerleider \& Mishkin, 1982, for related neuropsychological findings). For example, Carlson-Radvansky et al. (1999; Carlson-Radvansky \& Tang, 2000) demonstrated that people use object information to determine linguistic spatial relations. When asked to place a tube of toothpaste above a toothbrush, adults tended to place the toothpaste above the bristles of the toothbrush, not above the center of mass of the toothbrush. Such was not the case for unrelated object pairs, such as a tube of glue and a toothbrush. Similarly, Hirtle and Mascolo (1986) showed that object information influences peo- 
ple's spatial judgments about locations. After learning the locations of five government buildings (e.g., city hall, police station) and five recreational sites (e.g., playground, beach) on a fictitious map, adults judged the distance between pairs of items. Adults tended to underestimate distances between sites of the same type relative to equidistant sites of different types. That is, they recalled the police station and city hall as being closer together than the police station and the playground. These findings indicate that object information influences memory for locations. The key challenge is to specify the nature of this interaction.

One way to understand the interaction between objects and locations is to specify the nature of integration over time. For example, Hund and Plumert (2003) examined how object-location integration operates across development. In particular, they investigated how 7-, 9-, and 11-year-old children and adults use object information to remember locations. Participants learned the locations of 20 objects in an open, square box. In the related condition, objects belonging to the same semantic category (i.e., animals, vehicles, clothing, food) were located in the quadrants of the box. In the unrelated condition, the objects and locations were randomly paired. Participants in the related condition placed the objects belonging to the same category closer together than did participants in the unrelated condition, which suggests that children and adults integrate object and location information (see also Uttal et al., 2001). In the current study, we further specified the integration of objects and locations by examining how children and adults use object cues to organize the locations of objects, focusing on both task-level and developmental changes in stability and flexibility.

\section{Experiment 1}

The goal of Experiment 1 was to determine whether children and adults use object cues to organize locations into groups. In particular, can they organize the same locations into different groups depending on the pattern of object-location pairings? This experiment was similar to several recent studies in the object categorization domain in which the researchers presented the same items to all participants but provided different experiences with the items for people in different experimental conditions (e.g., Goldstone, 1995; Schyns \& Murphy, 1994; Schyns \& Rodet, 1997). For example, in one study, participants learned to categorize Martian cells_circles with various parts inside (Schyns \& Rodet, 1997). For some participants the relevant parts of the cells (e.g., the parts that determined category membership) were adjacent to one another, whereas for other participants the relevant parts were separated from each other. During test, participants were asked to classify novel Martian cells. Indeed, they categorized the new cells on the basis of their experience during training. That is, when the relevant parts were present but not adjacent, participants who were trained with adjacent features were less likely to classify these cells as category members than were participants trained with nonadjacent features. Thus, categorization was consistent with experience during the training phase. Examining performance in the present spatial categorization study relative to performance in previous object categorization studies provides important details regarding the domain generality of categorization processes (see also Madole \& Oakes, 1999; Thelen \& Smith, 1994). That is, is spatial categorization just as flexible on the basis of previous experience as is object categorization? Moreover, this experiment was a necessary step toward examining the stability and flexibility with which people organize locations into groups on the basis of object cues using a within-subject design (for a similar empirical approach, see Hund \& Plumert, 2005).

As in previous work, 7-, 9-, and 11-year-old children and adults learned the locations of 20 objects in a box. The objects belonged to four categories: animals, vehicles, clothing, and food. Objects belonging to the same semantic category were located close together in the box for all participants, but the specific pattern of object-location pairings differed across conditions. On the basis of previous findings, we expected that all four age groups would organize the locations into groups on the basis of the particular pattern of object-location pairings experienced during learning (e.g., Hund \& Plumert, 2003). This would confirm the salient nature of object cues for organizing locations into groups and set the stage for the second experiment, specifying the developmental emergence and balance of stability and flexibility.

\section{Method}

\section{Participants}

Twenty-four 7-year-olds, 24 nine-year-olds, 22 eleven-yearolds, and 24 adults participated, with approximately equal numbers of male and female participants in each group. The mean ages were 7 years 11 months (range $=7$ years 3 months to 8 years 7 months), 10 years 1 month (range $=9$ years 5 months to 10 years 8 months), 11 years 10 months (range $=11$ years 2 months to 12 years 5 months), and 20 years 7 months (range $=18$ years 9 months to 22 years 9 months), respectively. Three additional 7-year-olds were excluded because they did not reach the learning criterion. Children were recruited from a university laboratory school and from the surrounding communities. Parents received a letter describing the study and inviting children to participate. Most children were from middle- to upper middle-class European American families. Children received a small gift. Adults were students in undergraduate psychology courses at Illinois State University and received extra course credit.

\section{Apparatus and Materials}

A 32-in. long $\times$ 32-in. wide $\times 13$-in. high $(81.28 \mathrm{~cm} \times 81.28$ $\mathrm{cm} \times 33.02 \mathrm{~cm}$ ) open square box with white exterior walls and a Plexiglas floor was used as the experimental space. Three removable boards could be inserted below the Plexiglas to change the appearance of the floor: (a) a blue carpeted floor with yellow dots, (b) a blue carpeted floor with no dots, and (c) a grid of $x$ - and $y$-coordinates at 0.5 -in. $(1.27-\mathrm{cm})$ intervals.

The box contained 20 locations marked by 0.75 -in. $(1.90-\mathrm{cm})$ yellow dots (see Figure 1). The locations were arranged so that they could be organized in two specific ways, each forming four groups of five locations. In one case, the groups were along the sides of the box (i.e., the side groups; see Figure 2A), and in the other case, the groups were in the quadrants of the box (i.e., the quadrant groups; see Figure 2B). Eight target locations differenti- 


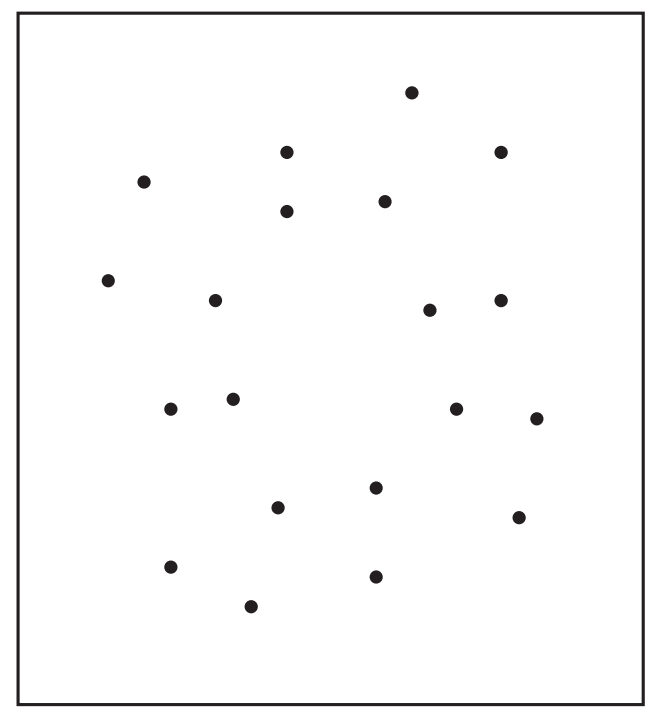

Figure 1. Diagram of the experimental apparatus and locations.

ated between the two patterns of organization. ${ }^{1}$ These target locations were included in different groups depending on whether the side or quadrant groups were highlighted (see Figure 2).

Twenty miniature objects belonging to four categories (i.e., animals, vehicles, clothing, and food) were used to help participants learn the locations: a pig, a dog, a cat, a chicken, a rabbit, a car, a van, a pick-up truck, a train engine, a cement mixer, a shirt, a hat, a pair of gloves, a skirt, a shoe, a jar of honey, an apple, a bag of chips, a pie, and a soda carton. The average length and width of the objects were 0.87 in. $(2.21 \mathrm{~cm})$ and $0.62 \mathrm{in} .(1.57 \mathrm{~cm})$, respectively.

\section{Design and Procedure}

Participants were randomly assigned to one of two conditions: side or quadrant. The conditions differed on the basis of the pattern of object-location pairings. For participants in the side condition, objects belonging to the same category were located along the sides of the box. For participants in the quadrant condition, in contrast, objects belonging to the same category were located in the quadrants of the box.

Participants were tested individually in a quiet room at the laboratory school. The open, square box was placed on the floor of the experimental room. The experiment was divided into a learning phase and a test phase. During the learning phase, participants learned the locations of the 20 objects in the box. First, they watched as the experimenter named the objects and placed them in the box one at a time in a random order. The assignment of categories to location groups and the assignment of category members to each location within a group were randomized for each participant. After all 20 objects were in their places, participants turned around while the experimenter removed the objects from the box. Then the experimenter gave the objects to participants one at a time and asked them to place the objects in the correct locations. The experimenter presented the objects in a new, random temporal order on each trial and immediately corrected any placement errors. Learning trials continued until participants could correctly place all 20 objects on the corresponding yellow dots in a single trial. The mean number of trials to criterion for 7-, 9-, and 11-year-olds and adults were $3.42(S D=1.53), 3.08(S D=$ $0.88), 2.73(S D=1.12)$, and $2.42(S D=0.94)$, respectively.

The test phase began immediately following the learning phase. First, the experimenter asked the participants to turn away from the box while the objects were removed. The experimenter also removed the floor with the yellow dots and replaced it with a plain blue floor. ${ }^{2}$ Participants then were asked to face the box and try to replace the objects in the correct locations without the aid of the yellow dots marking the locations. They were allowed to replace the objects in any temporal order they chose.

\section{Coding}

After participants left, the experimenter used the grid floor to record the position of each object (i.e., $x$ - and $y$-coordinates) to the nearest 0.5 in. $(1.27 \mathrm{~cm})$. The experimenter also decided which object was in each location. A placement was considered correct if it was in the correct position relative to the other objects. Occasionally, participants preserved the overall configurations of objects but incorrectly paired objects and locations. As in previous studies (e.g., Hund \& Plumert, 2002, 2003, 2005; Hund, Plumert, \& Benney, 2002; Plumert \& Hund, 2001), we used the $x$ - and $y$-coordinates for these locations, regardless of whether the correct objects were placed in the locations. We substituted $2.29 \%$ of the locations for 7 -year-olds (11 out of 480), 1.04\% for 9-year-olds (5 out of 480), $1.59 \%$ for 11 -year-olds ( 7 out of 440 ), and $1.25 \%$ for adults (6 out of 480). These substituted locations were used in all analyses. As in previous experiments, objects placed in an incorrect configuration were omitted from analyses. We omitted $1.88 \%$ of locations for 7-year-olds (9 out of 480 ), $0.63 \%$ for 9 -year-olds ( 3 out of 480 ), $0.45 \%$ for 11 -year-olds ( 2 out of 440 ), and $0 \%$ for adults (0 out of 480).

Intercoder reliability estimates of object placement were calculated for 16 randomly selected participants (17\% of the sample) as exact percentage agreement. For each of these participants, two coders judged which object was placed at each of the 20 locations. Coders agreed on $99.38 \%$ of the locations coded (318 out of 320 ).

\section{Measures}

Displacement scores. Two displacement scores were calculated on the basis of the eight target locations that differentiated between two potential patterns of organization (see Figure 2). The side displacement score reflected the degree to which participants systematically placed the eight target objects closer to the corners corresponding to the side groups than they actually were. Conversely, the quadrant displacement score reflected the degree to

\footnotetext{
${ }^{1}$ To ensure that these different patterns of organization were equated in terms of distance between locations, both the average distance between locations in each group (side: $M=5.68$ in. [14.43. cm]; quadrant: $M=$ $5.71 \mathrm{in} .[14.50 \mathrm{~cm}])$ and the average perimeter of the groups (side: $M=$ 28.41 in. [72.16 cm], quadrant: $M=28.54$ in. [72.49 cm]) were identical across organization types.

${ }^{2}$ Generally, it took the experimenter less than $1 \mathrm{~min}$ to remove the objects and change the floor, so the delay between learning and testing was very short.
} 

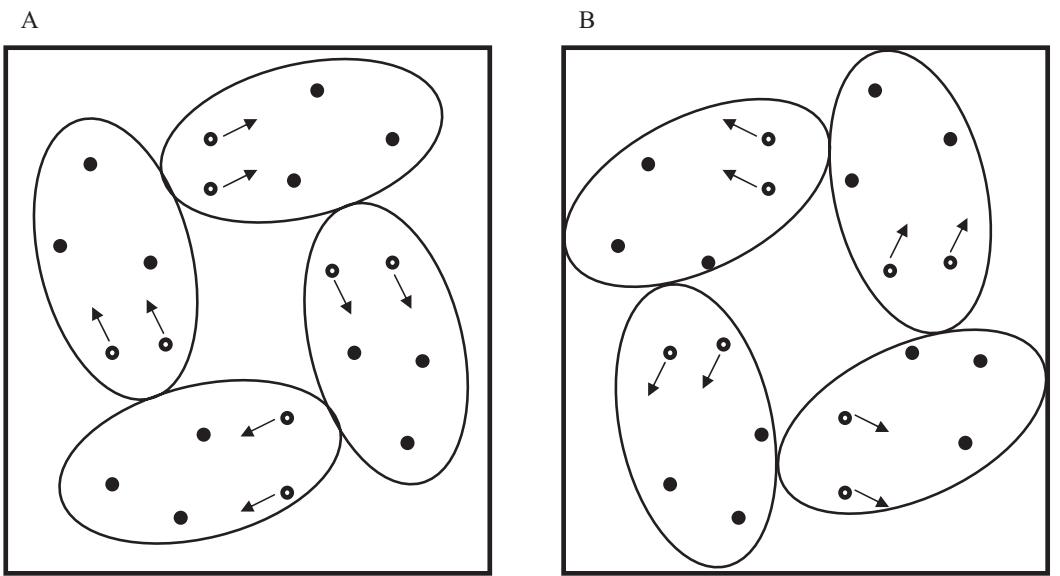

Figure 2. Locations belonging to the side groups (A) and the quadrant groups (B). Open circles mark the eight target locations. Arrows show the predicted patterns of displacement for the target locations. The ovals, open circles, and arrows are for illustration only.

which participants systematically placed the eight target objects closer to the corners corresponding to the quadrant groups than they actually were. To calculate the displacement scores, we first subtracted the distance between each remembered location and the corner from the distance between the corresponding actual location and the corner. We then averaged these differences across the eight target locations to obtain one side displacement score and one quadrant displacement score for each participant. These scores reflected the degree to which participants displaced locations toward the corners of the box (see also Hund \& Plumert, 2005; Plumert \& Hund, 2001). Conceptually, the displacement scores captured the degree of separation between different categories, a common measure of categorical organization (e.g., Cohen, Baldwin, \& Sherman, 1978; Markman \& Ross, 2003; Newcombe \& Liben, 1982; Tversky, 1977).

Error score. Participants received a single error score reflecting the degree to which they placed the objects near the actual locations. We calculated this score by determining the distance between each remembered location and the corresponding actual location and then averaging these distances over all 20 locations.

\section{Results}

\section{Patterns of Displacement}

The primary question of interest was whether children and adults used object relatedness to organize the locations into groups. To address this question, we entered side and quadrant displacement scores into an Age (7 years old, 9 years old, 11 years old, adult $) \times$ Condition $($ side, quadrant $) \times$ Score Type $($ side, quadrant $)$ analysis of variance (ANOVA) with the first two factors as between-subjects factors and the third factor as a within-subject factor. $^{3}$ This analysis yielded a significant main effect of condition, $F(1,86)=4.18, p<.05, \eta_{\mathrm{p}}^{2}=.05, M S_{\text {effect }}=0.76$, and a significant main effect of score type, $F(1,86)=5.79, p<.05$, $\eta_{\mathrm{p}}^{2}=.06, M S_{\text {effect }}=12.56$. These main effects were subsumed by a significant Condition $\times$ Score Type interaction, $F(1,86)=$ 78.64, $p<.01, \eta_{\mathrm{p}}^{2}=.48, M S_{\text {effect }}=170.52$. As predicted, simple effects tests revealed that side displacement was significantly greater than quadrant displacement in the side condition, $F(1$, 46) $=18.29, p<.01, \eta_{\mathrm{p}}^{2}=.28, M S_{\text {effect }}=44.86$, and that quadrant displacement was significantly greater than side displacement in the quadrant condition, $F(1,46)=77.91, p<.01, \eta_{\mathrm{p}}^{2}=$ $.63, M S_{\text {effect }}=137.74$ (see Figure 3 ).

\section{Error}

How accurately did participants place the objects during the test phase? To investigate this issue, we entered error scores into an Age ( 7 years old, 9 years old, 11 years old, adult $) \times$ Condition (side, quadrant) ANOVA with two between-subjects factors. The analysis yielded significant main effects of age, $F(3,86)=5.76$, $p<.01, \eta_{\mathrm{p}}^{2}=.17, M S_{\text {effect }}=1.62$, and of condition, $F(1,86)=$ $7.11, p<.01, \eta_{\mathrm{p}}^{2}=.08, M S_{\text {effect }}=2.00$. These main effects were subsumed by a marginally significant Age $\times$ Condition interaction, $F(3,86)=2.63, p<.056, \eta_{\mathrm{p}}^{2}=.08, M \mathrm{~S}_{\text {effect }}=0.74 .{ }^{4}$ Simple effects tests revealed that error differed across age groups for participants in the quadrant condition, $F(3,43)=7.21, p<.01$, $\eta_{\mathrm{p}}^{2}=.34, M S_{\text {effect }}=2.00$, but not for participants in the side condition, $F(3,43)=1.25, n s, \eta_{\mathrm{p}}^{2}=.08, M S_{\text {effect }}=0.36$. Tukey's honestly significant difference (HSD) follow-up tests indicated that in the quadrant condition, adults exhibited significantly less error than did all three child age groups. The remaining pairwise comparisons were not significant. The mean distance from correct locations was 3.07 in. ( $S E=0.20$ in. $[M=7.80 \mathrm{~cm}, S E=0.51$ $\mathrm{cm}]$ ) for 7-year-olds, $2.82 \mathrm{in}$. $(S E=0.14 \mathrm{in}$. $[M=7.16 \mathrm{~cm}, S E=$ $0.36 \mathrm{~cm}])$ for 9 -year-olds, 2.67 in. $(S E=0.12$ in. $[M=6.78 \mathrm{~cm}$,

${ }^{3}$ Although the side and quadrant scores were not completely independent, we analyzed these scores using a repeated measures design because this design allowed us to directly compare the scores as well as to compare performance across the age groups and conditions. These comparisons are important to our understanding of how children and adults use object cues to organize locations into groups.

${ }^{4}$ Note that the conventional alpha level $(p<.05)$ was used to determine statistical significance, whereas $p<.10$ was used to denote marginally significant results in all analyses. 


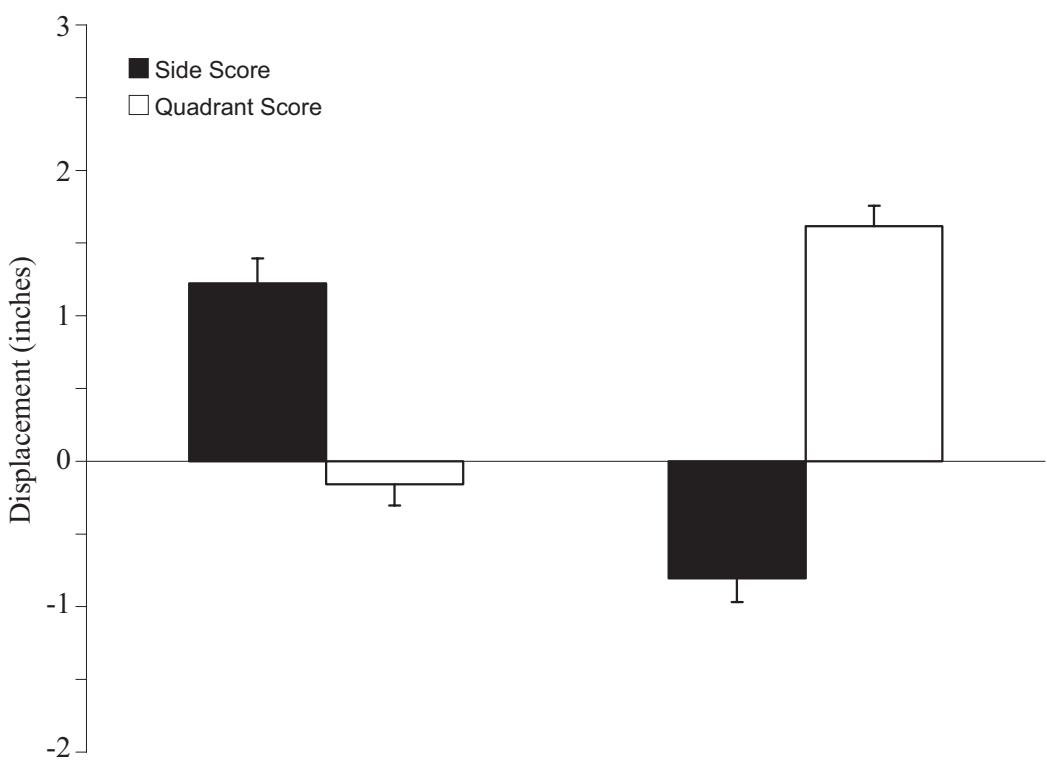

Side Condition

Quadrant Condition

Figure 3. Displacement scores (in inches) for each condition in Experiment 1. Error bars represent standard errors.

$S E=0.30 \mathrm{~cm}])$ for 11 -year-olds, and $2.11 \mathrm{in} .(S E=0.14 \mathrm{in} .[M=$ $5.36 \mathrm{~cm}, S E=0.36 \mathrm{~cm}]$ ) for adults. For participants in the side condition, the mean distance from correct locations was 2.52 in. $(S E=0.13$ in. $[M=6.40 \mathrm{~cm}, S E=0.33 \mathrm{~cm}])$ for 7-year-olds, 2.21 in. $(S E=0.12$ in. $[M=5.61 \mathrm{~cm}, S E=0.30 \mathrm{~cm}])$ for 9-year-olds, 2.53 in. $(S E=0.22$ in. $[M=6.43 \mathrm{~cm}, S E=0.56 \mathrm{~cm}])$ for 11 -year-olds, and 2.24 in. ( $S E=0.14$ in. $[M=5.69 \mathrm{~cm}, S E=0.36$ $\mathrm{cm}])$ for adults. These results suggest that the precision of memory for locations increased over development (particularly in the quadrant condition ${ }^{5}$ ), which is consistent with previous findings (e.g., Hund \& Plumert, 2002; Sandberg, Huttenlocher, \& Newcombe, 1996; Schutte \& Spencer, 2002; Schutte, Spencer, \& Schöner, 2003; Spencer \& Hund, 2003).

\section{Discussion}

The primary goal of this experiment was to investigate whether children and adults use different object-location pairings to organize the same set of locations into different groups. As predicted, all four age groups displaced the objects in ways that were consistent with the object-location groupings, which suggests that they used object relatedness to organize the same locations into different spatial categories. In particular, participants in the side condition placed the target objects closer to the side corners than to the quadrant corners of the box. In contrast, participants in the quadrant condition placed the target objects closer to the quadrant corners than to the side corners. These findings clearly demonstrate that children and adults used particular patterns of objectlocation pairings to organize locations into groups (see Hund \& Plumert, 2005, for similar results based on spatiotemporal experience). As such, the findings provide further support for the notion that object and location information interact in nontrivial ways. Moreover, the present results parallel findings from the object categorization domain (e.g., Goldstone, 1995; Schyns \& Murphy, 1994; Schyns \& Rodet, 1997), suggesting that the ability to tailor categories to specific experiences is domain general in nature (see also Madole \& Oakes, 1999). One challenge for future research is to examine the nature of similarities and differences in categorization across domains, providing detailed information regarding the dynamics of the underlying processes.

Although the present findings demonstrate that people can differentiate locations in different ways depending on the particular pattern of object-location pairings, it is not clear whether the same people can flexibly organize the same items differently when given different sets of pairings. As such, one goal of the second experiment was to examine the flexibility with which the same people organize locations into groups. That is, if the same people are given different patterns of object-location pairings involving the same set of locations, do they organize the locations into different groups? These findings would provide critical details about the nontrivial ways objects and locations interact. A second goal was to examine the stability of spatial category formation based on object cues over a 7-day delay, demonstrating the robust nature of object-location integration. A final goal was to specify the emergence and balance of stability and flexibility across development.

\footnotetext{
${ }^{5}$ This asymmetry in the developmental decline in error across conditions is consistent with previous work demonstrating improved flexibility with quadrant organization relative to side organization (Hund \& Plumert, 2005). Together, these findings highlight the supportive nature of perceptual cues underlying the quadrant organization in this task. In addition, they are consistent with children's enhanced ability to use perceptual cues over development (e.g., Huttenlocher et al., 1994; Plumert \& Hund, 2001).
} 


\section{Experiment 2}

In Experiment 2, we sought to specify the dynamics of objectlocation integration over multiple time scales. In particular, we focused on the stability and flexibility with which children and adults organize locations into groups on the basis of object cues, illuminating processing over both task-level and developmental time scales. The experimental task used in Experiment 2 included two testing sessions separated by approximately 7 days. ${ }^{6}$ The first session was identical to the session included in Experiment 1. At the beginning of the second session, participants were asked to replace the original objects in the correct locations without the aid of the dots. This repeated assessment following a long delay provided an index of category stability based on object-location pairings. After this delay test, participants learned the locations of a new set of related objects using a new pattern of object-location pairings. The locations were identical to those learned at the first session; however, the pattern of organization of object-location pairings was opposite to that experienced in the first session, providing an index of flexibility.

On the basis of the results from our first experiment and from previous findings using a similar empirical approach (Hund \& Plumert, 2005), we expected that children and adults would organize the locations into groups on the basis of the pattern of object relatedness at the first session. Moreover, we expected that this organization would be relatively stable across a long delay for all age groups, revealing a similar pattern of category stability across development (for similar results, see Hund \& Plumert, 2005). We also expected that older children and adults would demonstrate flexibility in their organization of locations into groups. That is, we predicted that they would shift their organization following a change in object-location pairings at the second session. In contrast, we expected that the younger children would show less clear evidence of flexibility across sessions. These findings would underscore the relatively early emergence of category stability and the increase in flexibility across middle childhood (for similar results using this empirical approach, see Hund \& Plumert, 2005; see also Deák et al., 2004; Diamond \& Doar, 1989; Yerys \& Munakata, 2006; Zelazo et al., 1996).

\section{Method}

\section{Participants}

Twenty-three 7-year-olds, 21 nine-year-olds, 20 eleven-yearolds, and 24 adults participated, with approximately equal numbers of male and female participants in each age group. The mean ages were 7 years 9 months (range $=7$ years 3 months to 8 years 4 months), 9 years 6 months (range $=8$ years 9 months to 10 years 1 month), 11 years 7 months (range $=10$ years 11 months to 12 years 4 months), and 20 years 11 months (range $=18$ years 4 months to 25 years 0 months), respectively. Five additional 7 -yearolds were excluded because they did not reach the learning criterion (3 during Session 1 and 2 during Session 2). One additional 11-year-old was excluded because of failure to reach the learning criterion at Session 1. One additional adult was excluded because the participant was unable to return for the second session. Participants were recruited and compensated in the same manner as in Experiment 1.

\section{Apparatus and Materials}

The box and locations were the same as those used in Experiment 1 (see Figure 1). In addition to the 20 objects used in the previous study (Set A), a second set of 20 objects was used (Set B): a cow, a frog, a groundhog, a bee, a fish, a tractor, a taxi, a boat, a dump truck, a police car, a sandal, a dress, a pair of shorts, a helmet, a tank top, a cake, a jar of peanut butter, a bottle of milk, a box of cereal, and a bunch of bananas. The average length and width of the objects were $0.97 \mathrm{in} .(2.46 \mathrm{~cm})$ and $0.63 \mathrm{in} .(1.60 \mathrm{~cm})$, respectively.

\section{Design and Procedure}

Participants completed two sessions. The first session was identical to that used in Experiment 1. As in Experiment 1, the related objects were placed in locations either along the sides of the box or in the quadrants of the box at Session 1. Half of the participants learned the locations of the objects used in the previous experiment (Set A), whereas the remaining participants learned the locations of a different set of objects (Set B). The mean number of trials to criterion was $3.57(S D=1.67)$ for 7-year-olds, $3.19(S D=1.21)$ for 9-year-olds, $1.90(S D=1.02)$ for 11-year-olds, and $2.08(S D=$ 1.06) for adults.

Participants completed a second session approximately 7 days $(M=7.01$ days, $S D=2.13$ days $)$ later. First, participants attempted to replace the original objects in the box without the dots marking the locations (i.e., the delay test phase). Then they learned a new set of objects paired with the (same) locations in the box using a new pattern of object-location pairings. That is, participants who experienced the related objects along the sides of the box during the first session experienced the related objects in the quadrants of the box during the second session. In contrast, participants who experienced the related objects in the quadrants of the box during the first session experienced the related objects along the sides of the box during the second session. The mean number of trials to criterion was $3.22(S D=1.51)$ for 7-year-olds, $2.67(S D=1.02)$ for 9-year-olds, $2.25(S D=1.41)$ for 11 -yearolds, and $1.71(S D=0.91)$ for adults. Following learning, participants attempted to replace the new objects without the aid of the dots.

\section{Coding and Measures}

The coding and measures were identical to those used in Experiment 1 . In this experiment, however, object locations for the delay test phase were coded from digital pictures of the objects. The experimenter took a picture of the objects in the box (containing the grid floor) using a remote-control-operated Olympus (Center Valley, PA) C-3040Z digital camera mounted on the ceiling directly above the apparatus. Later, the digital pictures were viewed on a 20-in. (50.80-cm) Planar (Beaverton, OR) PL2010M monitor, and the object coordinates were coded to the nearest 0.5 -in. $(1.27 \mathrm{~cm})$.

\footnotetext{
${ }^{6}$ Conceptually, this delay was chosen to provide a strong test of stability over a lengthy delay. Practically, conducting sessions 7 days apart allowed precise control of the delay period, because both school and family schedules tend to vary daily but are similar from week to week.
} 
As in Experiment 1, we used the $x$ - and $y$-coordinates for the locations, regardless of whether the correct objects were placed in the locations. These substituted locations were used in all analyses. As in Experiment 1, objects placed in an incorrect configuration were omitted from analyses. The mean percentage of substituted locations for each age group and session was between $0 \%$ and $20 \% .^{7}$ The mean percentage of omitted locations for each age group and session was between $0 \%$ and $4 \%$ (see Table 1).

Intercoder reliability estimates of object placement for each test session were calculated for 8 randomly selected participants $(9 \%$ of the sample) as exact percentage agreement. Two coders judged which object was placed at each of the 20 locations for each of these participants and sessions. Coders agreed on $99.17 \%$ of the locations coded (476 out of 480).

\section{Results}

The goal of Experiment 2 was to investigate the stability and flexibility with which children and adults use object cues to form spatial categories. First, we examined category stability by comparing performance across Session 1 and the delay phase. We expected spatial categories to be relatively stable for all age groups; thus, the patterns of displacement of object locations should be similar across repeated sessions for all ages. We also examined changes in error over a 7-day delay, predicting that memory precision would decrease over time.

\section{Category Stability: Comparison of Results From Session 1 and Delay Phase}

Patterns of displacement. To examine whether the pattern of displacement was stable across repeated test sessions, we entered side and quadrant displacement scores from Session 1 and the delay phase into an Age (7 years old, 9 years old, 11 years old, adult $) \times$ Condition (side, quadrant $) \times$ Score Type (side, quadrant) $\times$ Session (Session 1, delay phase) mixed model ANOVA. The analysis yielded a marginally significant main effect of age,

Table 1

Mean Percentage of Locations Substituted and Omitted for Each Age Group and Session in Experiment 2

\begin{tabular}{lrc}
\hline & \multicolumn{2}{c}{$\%$ locations } \\
\cline { 2 - 3 } Age and session & Substituted & Omitted \\
\hline 7-year-olds & & \\
Session 1 & 1.30 & 0.65 \\
Delay phase & 16.96 & 2.61 \\
Session 2 & 0.87 & 0.43 \\
9-year-olds & & \\
Session 1 & 1.90 & 0.48 \\
Delay phase & 16.43 & 3.81 \\
Session 2 & 0.48 & 0.00 \\
11-year-olds & & \\
Session 1 & 0.50 & 0.75 \\
Delay phase & 13.25 & 2.25 \\
Session 2 & 0.00 & 0.00 \\
Adults & & \\
Session 1 & 0.83 & 0.00 \\
Delay phase & 19.38 & 0.04 \\
Session 2 & 0.00 & \\
\hline
\end{tabular}

$F(3,80)=2.69, p<.053, \eta_{\mathrm{p}}^{2}=.09, M S_{\text {effect }}=1.49$. Tukey's HSD follow-up tests indicated that all three child age groups placed the target objects significantly closer to the corners of the box than did the adults ( 7 years: $M=0.56$ in., $S E=0.08$ in. [ $M=$ $1.42 \mathrm{~cm}, S E=0.20 \mathrm{~cm}$ ]; 9 years: $M=0.43$ in., $S E=0.08$ in. $[M=1.09 \mathrm{~cm}, S E=0.20 \mathrm{~cm}] ; 11$ years: $M=0.43$ in., $S E=0.08$ in. $[M=1.09 \mathrm{~cm}, S E=0.20 \mathrm{~cm}]$; adults: $M=0.25$ in., $S E=0.08$ in. $[M=0.64 \mathrm{~cm}, S E=0.20 \mathrm{~cm}])$. The remaining pairwise comparisons were not significant. These findings are consistent with previous results demonstrating a decline in corner bias during childhood (Hund \& Plumert, 2005; Plumert \& Hund, 2001; see also Uttal, 1994, 1996).

The analysis also yielded a significant main effect of condition, $F(1,80)=10.21, p<.005, \eta_{\mathrm{p}}^{2}=.11, M S_{\text {effect }}=5.67$, and $\mathrm{a}$ significant Score Type $\times$ Condition interaction, $F(1,80)=64.79$, $p<.001, \eta_{\mathrm{p}}^{2}=.45, M S_{\text {effect }}=283.91$. These effects were subsumed by a significant Score Type $\times$ Condition $\times$ Session interaction, $F(1$, $80)=12.00, p<.005, \eta_{\mathrm{p}}^{2}=.13, M S_{\text {effect }}=9.63$ (see Figure 4). Simple effects tests yielded significant Score Type $\times$ Condition interactions at Session $1, F(1,86)=52.97, p<.001, \eta_{\mathrm{p}}^{2}=.38$, $M S_{\text {effect }}=95.38$, and at the delay phase, $F(1,86)=59.99, p<.001$, $\eta_{\mathrm{p}}^{2}=.41, M S_{\text {effect }}=202.35$. As expected, in Session 1, side displacement was significantly greater than quadrant displacement for participants in the side condition, $F(1,43)=28.42, p<.001, \eta_{\mathrm{p}}^{2}=.40$, $M S_{\text {effect }}=55.50$, and quadrant displacement was significantly greater than side displacement for participants in the quadrant condition, $F(1$, $43)=24.55, p<.001, \eta_{\mathrm{p}}^{2}=.36, M S_{\text {effect }}=40.47$. Similarly, in the delay phase, side displacement was significantly greater than quadrant displacement for participants in the side condition, $F(1,43)=33.97$, $p<.001, \eta_{\mathrm{p}}^{2}=.44, M S_{\text {effect }}=135.77$, and quadrant displacement was significantly greater than side displacement for participants in the quadrant condition, $F(1,43)=26.07, p<.001, \eta_{\mathrm{p}}^{2}=.38, M S_{\text {effect }}=$ 71.66. Despite the similarities in the overall pattern of displacement across sessions (indicative of stability), the magnitude of displacement increased across the delay, lending support to the notion that categorical bias increases as the fine-grained precision of locations becomes less certain over time (Hund \& Plumert, 2002; Hund \& Spencer, 2003; Huttenlocher, Hedges, \& Duncan, 1991; Schutte \& Spencer, 2002; Spencer \& Hund, 2002, 2003). These findings indicate that the organization of locations on the basis of object cues evident during the first session was stable across a 7-day delay (see also Hund \& Plumert, 2005).

Error. How might error change over time? We expected that participants' memory for exact locations would become less precise as the time between learning and test increased. Error scores were entered into an Age (7 years old, 9 years old, 11 years old, adult) $\times$ Condition (side, quadrant) $\times$ Session (Session 1 , delay phase) mixed model ANOVA. The analysis yielded a significant main effect of session, $F(1,80)=52.69, p<.001, \eta_{\mathrm{p}}^{2}=.40, M S_{\text {effect }}=14.26$. As

\footnotetext{
${ }^{7}$ The percentage of substituted locations was larger at the delay phase than at either Session 1 or 2. This increase in mispairings of objects and locations (without a corresponding increase in incorrect location placements, i.e., omissions) suggests that the configurations of locations were very stable across delays. Moreover, general details about the categorical relations between objects and locations (e.g., which set of objects went with each group of locations) were highly stable. In contrast, the precise pairing of objects and locations within those groups was much less stable over a lengthy delay.
} 


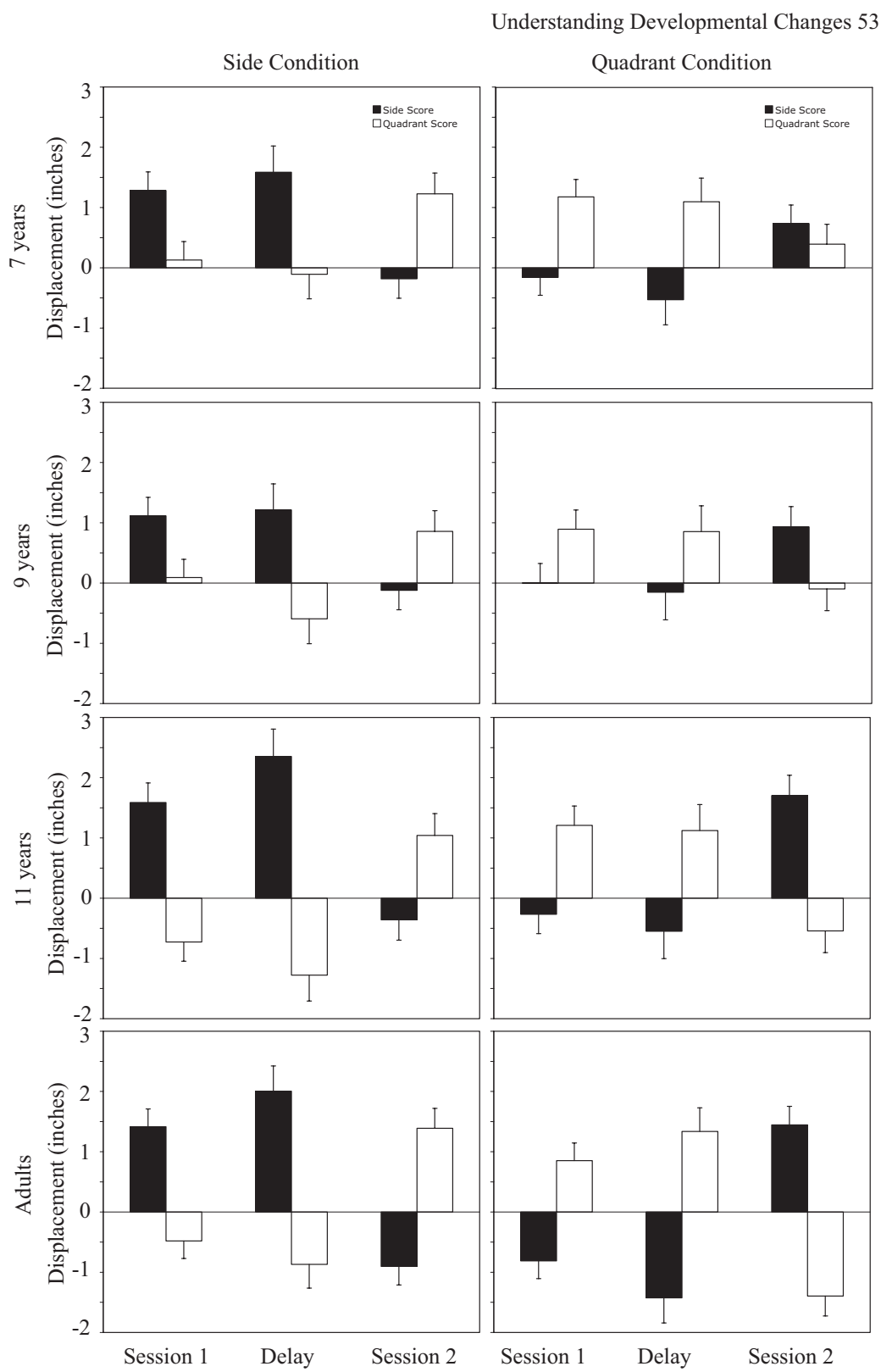

Figure 4. Displacement scores (in inches) for each age group, condition, and session in Experiment 2. Error bars represent standard errors.

expected, participants exhibited significantly greater error during the delay phase ( $M=3.06$ in., $S E=0.09$ in. $[M=7.77 \mathrm{~cm}, S E=0.23$ $\mathrm{cm}]$ ) than during Session 1 ( $M=2.49$ in., $S E=0.07$ in. $[M=6.32$ $\mathrm{cm}, S E=0.18 \mathrm{~cm}])$. These results are consistent with findings from other studies specifying declines in the precision of location memory over delay (e.g., Engebretson \& Huttenlocher, 1996; Hund \& Plumert, 2002, 2005; Hund \& Spencer, 2003).

The analysis also yielded a significant main effect of age, $F(3$, $80)=7.54, p<.001, \eta_{\mathrm{p}}^{2}=.22, M S_{\text {effect }}=5.64$. Tukey's HSD follow-up tests indicated that all three child age groups exhibited significantly greater error than did the adults. The remaining pairwise comparisons were not significant. The mean distance from correct locations was 3.11 in. $(S E=0.13$ in. $[M=7.90 \mathrm{~cm}, S E=0.33 \mathrm{~cm}])$ for 7-year-olds, $2.86 \mathrm{in}$. $(S E=0.13 \mathrm{in}$. $[M=7.26 \mathrm{~cm}, S E=0.33 \mathrm{~cm}])$ for 9-year-olds, $2.85 \mathrm{in}$. $(S E=0.14$ in. $[M=7.24 \mathrm{~cm}, S E=0.36 \mathrm{~cm}])$ for 11-year-olds, and 2.29 in. $(S E=0.13$ in. $[M=5.82 \mathrm{~cm}, S E=$ $0.33 \mathrm{~cm}]$ ) for adults. As in Experiment 1, these results suggest that memory precision increased over development.

\section{Category Flexibility: Comparison of Results From Session 1 and Session 2}

Comparing performance across Sessions 1 and 2 (for which the pattern of object-location pairings differed) provided an index of 
flexibility. We expected that older children and adults would exhibit such flexibility but that flexibility across sessions would be less clearly evident for the younger children. We also examined patterns of error during the two sessions, predicting that memory precision would be similar, given that the test phase immediately followed the learning phase during both sessions.

Patterns of displacement. One primary question of interest was whether children and adults flexibly form spatial categories on the basis of object cues. More specifically, we examined whether participants displaced the same locations in different ways, consistent with the differing patterns of object-location pairings experienced across sessions. We expected that 11-year-old children and adults would flexibly shift organization on the basis of object cues; thus, we predicted that their patterns of displacement would differ across sessions. In contrast, we expected that the 7- and 9-year-olds would show less consistent evidence of flexibility, which would indicate that flexibility increases across childhood. Side displacement and quadrant displacement scores from Session 1 and Session 2 were entered into an Age (7 years old, 9 years old, 11 years old, adult $) \times$ Condition $($ side, quadrant $) \times$ Score Type (side, quadrant) $\times$ Session (Session 1 , Session 2) mixed model ANOVA. This analysis yielded a significant main effect of age, $F(3,80)=7.63, p<.001, \eta_{\mathrm{p}}^{2}=.22, M S_{\text {effect }}=2.52$; a significant Session $\times$ Condition interaction, $F(1,80)=5.10, p<.05, \eta_{\mathrm{p}}^{2}=$ $.06, M S_{\text {effect }}=1.02$; and a significant Score Type $\times$ Session $\times$ Condition interaction, $F(1,80)=80.28, p<.001, \eta_{\mathrm{p}}^{2}=.50$, $M S_{\text {effect }}=201.68$. These effects were subsumed by a significant Score Type $\times$ Session $\times$ Condition $\times$ Age interaction, $F(3,80)=$ $3.11, p<.05, \eta_{\mathrm{p}}^{2}=.11, M S_{\text {effect }}=7.82$ (see Figure 4). Simple effects tests revealed a significant Score Type $\times$ Session $\times$ Condition interaction for 7-year-olds, $F(1,21)=11.16, p<.005$, $\eta_{\mathrm{p}}^{2}=.35, M S_{\text {effect }}=25.80$; for 9-year-olds, $F(1,19)=9.01, p<$ $.01, \eta_{\mathrm{p}}^{2}=.32, M S_{\text {effect }}=20.18$; for 11-year-olds, $F(1,18)=$ 28.46, $p<.001, \eta_{\mathrm{p}}^{2}=.61, M S_{\text {effect }}=69.19$; and for adults, $F(1$, $22)=37.69, p<.001, \eta_{\mathrm{p}}^{2}=.63, M S_{\text {effect }}=113.31$.

Additional planned comparisons revealed that for the 7-yearolds in the quadrant condition, quadrant displacement was marginally greater than side displacement at Session $1, F(1,11)=$ 4.17, $p<.067, \eta_{\mathrm{p}}^{2}=.28, M S_{\text {effect }}=10.71$, but side displacement and quadrant displacement did not differ at Session $2, F(1,11)=$ $.31, n s, \eta_{\mathrm{p}}^{2}=.03, M S_{\text {effect }}=0.70$. For 7 -year-olds in the side condition, side displacement and quadrant displacement did not differ at Session $1, F(1,10)=3.19, n s, \eta_{\mathrm{p}}^{2}=.24, M S_{\text {effect }}=7.31$, but quadrant displacement was marginally greater than side displacement at Session $2, F(1,10)=3.56, p<.089, \eta_{\mathrm{p}}^{2}=.26$, $M S_{\text {effect }}=10.94$. These findings indicate very little evidence of flexibility for 7-year-olds, as we expected.

For the 9-year-olds in the quadrant condition, quadrant displacement and side displacement did not differ at Session $1, F(1,9)=$ $3.12, n s, \eta_{\mathrm{p}}^{2}=.26, M S_{\text {effect }}=3.99$, or at Session 2, $F(1,9)=2.03$, $n s, \eta_{\mathrm{p}}^{2}=.18, M S_{\text {effect }}=5.30$. Nine-year-olds in the side condition exhibited side displacement that was marginally greater than quadrant displacement at Session $1, F(1,10)=3.73, p<.083, \eta_{\mathrm{p}}^{2}=$ $.72, M S_{\text {effect }}=5.78$, but quadrant displacement and side displacement did not differ at Session $2, F(1,10)=3.05, n s, \eta_{\mathrm{p}}^{2}=.23$, $M S_{\text {effect }}=5.26$. These findings indicate very little evidence of flexibility for 9-year-olds, confirming our predictions.

In contrast, 11-year-olds in the quadrant condition exhibited significantly greater quadrant displacement than side displacement at Session $1, F(1,9)=5.59, p<.05, \eta_{\mathrm{p}}^{2}=.38, M S_{\text {effect }}=10.87$, and significantly greater side displacement than quadrant displacement at Session 2, $F(1,9)=15.52, p<.005, \eta_{\mathrm{p}}^{2}=.63, M S_{\text {effect }}=$ 25.20. Moreover, 11-year-olds in the side condition exhibited significantly greater side displacement than quadrant displacement at Session $1, F(1,9)=15.25, p<.005, \eta_{\mathrm{p}}^{2}=.63, M S_{\text {effect }}=$ 26.87, and significantly greater quadrant displacement than side displacement at Session 2, $F(1,9)=8.83, p<.05, \eta_{\mathrm{p}}^{2}=.50$, $M S_{\text {effect }}=9.83$. These findings suggest that the magnitude of displacement was slightly larger at Session 2 than at Session 1. It is important to note, however, that the findings also reveal clear evidence of flexibility for 11-year-olds, just as we predicted.

Similarly, as expected, adults in the quadrant condition exhibited significantly greater quadrant displacement than side displacement at Session $1, F(1,11)=15.32, p<.05, \eta_{\mathrm{p}}^{2}=.58, M S_{\text {effect }}=$ 16.61, and significantly greater side displacement than quadrant displacement at Session 2, $F(1,11)=20.41, p<.005, \eta_{\mathrm{p}}^{2}=.65$, $M S_{\text {effect }}=48.42$. Moreover, adults in the side condition exhibited significantly greater side displacement than quadrant displacement at Session $1, F(1,11)=10.01, p<.01, \eta_{\mathrm{p}}^{2}=.48, M S_{\text {effect }}=$ 21.56 , and significantly greater quadrant displacement than side displacement at Session 2, $F(1,11)=14.09, p<.005, \eta_{\mathrm{p}}^{2}=.56$, $M S_{\text {effect }}=31.49$. Again, these findings suggest that the magnitude of displacement was slightly larger at Session 2 than at Session 1. It is important to note, however, that the findings also reveal clear evidence of flexibility for adults, just as we predicted.

Error. Was error similar across the two sessions when the length of delay between learning and test was identical (i.e., the test phase occurred directly after the learning phase)? To address this issue, error scores were entered into an Age (7 years old, 9 years old, 11 years old, adult $) \times$ Condition (side, quadrant) $\times$ Session (Session 1, Session 2) mixed model ANOVA. As expected, there were no significant session effects, indicating that error was similar across the two sessions when the test phase followed the learning phase directly. Nonetheless, the analysis yielded a significant main effect of age, $F(3,80)=4.68, p<.01$, $\eta_{\mathrm{p}}^{2}=.15, M S_{\text {effect }}=2.36$. Tukey's HSD follow-up tests indicated that 7-year-olds exhibited significantly greater error than did adults. The remaining pairwise comparisons were not significant. The mean distance from correct locations was 2.79 in. ( $S E=0.11$ in. $[M=7.09 \mathrm{~cm}, S E=0.28 \mathrm{~cm}])$ for 7-year-olds, $2.51 \mathrm{in}$. $(S E=$ 0.11 in. $[M=6.38 \mathrm{~cm}, S E=0.28 \mathrm{~cm}])$ for 9-year-olds, $2.44 \mathrm{in}$. $(S E=0.11$ in. $[M=6.20 \mathrm{~cm}, S E=0.28 \mathrm{~cm}])$ for 11-year-olds, and 2.24 in. $(S E=0.10$ in. $[M=5.69 \mathrm{~cm}, S E=0.25 \mathrm{~cm}])$ for adults. As in Experiment 1, the precision of location memory increased over development.

\section{Discussion}

The central questions of interest focused on the stability and flexibility with which children and adults organize locations into groups on the basis of object relatedness. As expected, children and adults tended to place the target objects closer to the corners consistent with the pattern of object-location pairings experienced than to the inconsistent corners during Session 1 and the delay phase. These findings provide clear evidence that spatial category formation based on object relatedness was stable for both children and adults over a 7-day delay, highlighting the powerful, enduring nature of interactions between objects and locations. 
As predicted, 11-year-olds and adults demonstrated flexibility following a change in object-location pairings at Session 2. In contrast, the 7- and 9-year-old children did not exhibit clear shifts in their patterns of displacement across sessions, revealing a lack of flexibility in organization following the change in objectlocation pairings at Session 2. Instead, it seems as if the pattern of organization from Session 1 interfered with the learning and/or retention of a second organizational pattern for these younger children, leading to a mixture of organizations (i.e., no clear pattern) at Session 2. These findings suggest that the flexibility with which children organize locations into groups on the basis of object cues increases across childhood, as they become more proficient at marshalling multiple patterns of organization suitable for specific task contexts. Thus, as expected, stability was similar across age groups, whereas flexibility increased across the age range studied. These findings support the notion that children first exploit object cues to stably maintain an initial categorical organization and only later exploit these same cues to flexibly alter an existing categorical organization in light of task changes. This general pattern is evident in many domains in which children first demonstrate successful organization on the basis of a particular cue or rule (e.g., "Sort cards containing pictures of blue flowers and red trucks on the basis of color: Red ones go here, and blue ones go here") and only later demonstrate a successful shift in organization on the basis of a new cue or rule (e.g., "Sort the same cards on the basis of shape: Flowers go here, and trucks go here"; Kirkham et al., 2003; Zelazo et al., 1996; see also Blaye \& Bonthoux, 2001; Deák et al., 2004; Diamond \& Doar, 1989). Future research is needed to further specify the precise mechanisms by which children move toward flexibility.

\section{General Discussion}

\section{Category Stability and Flexibility}

One central goal of this investigation was to specify developmental changes in category stability and flexibility, particularly focusing on the relation between these processes over development. Seven-, 9-, and 11-year-old children and adults consistently used object relatedness to organize locations into categories. This pattern of organization was evident both immediately following learning and following a 7-day delay. Thus, children and adults stably maintained organization based on object cues across a lengthy delay, demonstrating developmental continuity in category stability within the age range and task employed here. This impressive ability to maintain information over lengthy delays evident relatively early in development undoubtedly relies on robust coding of object and location information that can persist over time. Indeed, recent findings indicate that the temporal persistence of memory increases dramatically during infancy and toddlerhood (e.g., Bauer, 2004, 2005; Oakes, Ross-Sheehy, \& Luck, 2006; Rose, 1981; Rose, Feldman, \& Jankowski, 2003), setting the stage for the impressive stability evident here (see the theoretical review below for specific explanatory details).

It is important to note that the present results also show that the flexibility with which children and adults organized locations into groups on the basis of object cues increased across development. Only older children and adults consistently shifted to a new pattern of organization following a change in the pattern of object- location pairings. Younger children did not show clear evidence of a new pattern of organization. Instead, they evinced a mixture of patterns during the second session, which suggests they had difficulty using divergent strategies in the task contexts tested here. These findings are consistent with others in the literature, suggesting that flexibility in category formation (and in responding more generally) increases across childhood (e.g., Blaye \& Bonthoux, 2001; Deák et al., 2004; Hund \& Plumert, 2005; Oakes, Plumert, Lansink, \& Merryman, 1996; Plumert, 1994; Smith \& Samuelson, 1997). What mechanisms might underlie these changes? It is possible that flexibility increases across development as children gain access to nonobvious cues and gain experience with categorizing (or organized responding) in many ways (e.g., Hund \& Plumert, 2005; Madole \& Oakes, 1999; Oakes et al., 1996; Plumert, 1994; Smith \& Samuelson, 1997). In addition, it is possible that the ability to shift to a new pattern of responding is related to developmental improvements in speed of processing and working memory across childhood, which both reduce proactive interference and increase response shifting across development (for related ideas, see Kail, 2002). In fact, these mechanisms might interact in nontrivial ways such that improvements in cognitive processing facilitate responding based on less obvious cues and experience with multiple (nonobvious) cues drives changes in underlying cognitive processing (for theoretical discussion of such complex interactions, see Plumert, Hund, \& Recker, 2007; Thelen, Schöner, Scheier, \& Smith, 2001).

Thus far, our discussion has focused on understanding cognitive stability and cognitive flexibility in isolation, tracing their individual profiles of change across development. Although specifying these details represents progress toward important contemporary goals (e.g., understanding the development of executive function) that will help shed light on both typical and atypical patterns of development (Carlson, 2005; Daniels, Toth, \& Jacoby, 2006; Diamond, 2006; Hughes, 1998; Pennington \& Ozonoff, 1996; Welsh, Pennington, \& Groisser, 1991; Zelazo, Carter, Reznick, \& Frye, 1997), we contend that the field needs an even more dynamic and intricate understanding to truly make progress in uncovering the mechanisms of change over time. In particular, we seek to understand not only cognitive stability and flexibility in isolation but also the relation between stability and flexibility processes and, most important, how this relation evolves over developmental time. This focus is consistent with dynamic systems views, which contend that responding emerges from real-time cognitive processes (e.g., perceiving and remembering) involving the soft assembly of multiple cues in a given task situation on the basis of an extended history of responding that unfolds within the task and across development (Jones \& Smith, 1993; Smith \& Samuelson, 1997; Thelen \& Smith, 1994). In particular, stability results from the repeated combination of cues in task contexts, leading to similarities in emergent categories over time, whereas flexibility results from the combination of different sources of information and from differences in the task at hand.

What do the present findings reveal about the emergence and balance of stability and flexibility over development? Our findings clearly indicate that children first use available cues, such as object-location pairings, to organize locations into groups that persist over time, demonstrating stability. Then they make use of object cues to flexibly shift to new patterns of organization, demonstrating flexibility. Taken together, these findings underscore 
the idea that stability emerges prior to flexibility. This pattern is evident in many domains in which children first demonstrate successful organization on the basis of one particular cue and only later demonstrate a successful shift in organization on the basis of a new cue (e.g., dimensional change card sorting; Kirkham et al., 2003; Zelazo et al., 1996; categorical organization; Blaye \& Bonthoux, 2001; Deák et al., 2004; Hund \& Plumert, 2005). Future longitudinal and microgenetic research is needed to specify the dynamic evolution of categories (and cognitive processes more generally) over multiple time scales (see Brace et al., 2006, for results showing the utility of this approach).

\section{Interactions Between Objects and Locations}

The results of this investigation clearly show that children and adults used object cues to remember locations. In Experiment 1, children and adults exhibited displacement consistent with the object-location pairings they experienced. This finding was replicated in Experiment 2. Moreover, Experiment 2 showed that children and adults maintained such organization across a 7-day delay. It is interesting that the flexibility with which children shifted to a new pattern of organization on the basis of object cues increased dramatically across development. Together, these findings support the notion that object information influences memory for locations. As such, the findings add to a growing body of work showing that object and location information interact in nontrivial ways (e.g., Carlson-Radvansky et al., 1999; Hirtle \& Mascolo, 1986; Hund \& Plumert, 2003; Postma et al., 2004; Shelton \& McNamara, 2004). Moreover, they represent a step forward in addressing a key contemporary challenge- - understanding the nature of the integration of object and location information. In the section below, we describe two theoretical models that might help specify the mechanisms of integration.

\section{Explaining the Dynamics of Development}

How do children and adults use object cues to organize locations into groups that are both stable and flexible? The following section evaluates two prominent models in an attempt to answer this question by specifying the mechanisms of such interactions. In particular, we focus on two key aspects of cognition revealed here: (a) the complex dynamics of the object-location interactions evident across development, and (b) the emergence and balance of stability and flexibility across development.

\section{The Category Adjustment (CA) Model}

According to the CA model proposed by Huttenlocher et al. (1991), estimates of location result from the combination of two types of information. Because memory for fine-grained information (e.g., distance and direction from an edge) is inexact, people adjust their location estimates on the basis of categorical information (e.g., region membership). According to the model, adjustments based on spatial category information lead to systematic distortions toward the centers of spatial categories. These distortions necessarily result in the overestimation of differences across category boundaries.

The present findings add to a growing body of work suggesting that people use a variety of cues to organize locations into groups, such as object relatedness (Hund \& Plumert, 2003), spatiotemporal organization (Hund \& Plumert, 2005; Hund et al., 2002), and geometric boundaries (Huttenlocher et al., 1991; Huttenlocher, Newcombe, \& Sandberg, 1994; Plumert \& Hund, 2001). How might the CA model account for these findings showing that object relatedness influences location estimation? It is possible that object information serves as a cue for defining spatial categories because it highlights which locations go together. Once formed, these spatial categories then could be used during location estimation, thereby leading to biases in estimation. Although these ideas are consistent with broad conceptual details outlined in the CA model, future model development is needed to specify the exact mechanisms of integration of object and location cues. This work has the potential to shed light on how people integrate diverse cues to remember objects and locations (see Hund \& Plumert, 2002, 2005; Huttenlocher, Hedges, \& Vevea, 2000, for related ideas).

Our findings also highlight the dynamic emergence and balance of cognitive stability and flexibility evident during childhood. In particular, stability emerges prior to flexibility. Although the CA model does not incorporate dynamic aspects in its mathematical implementation, according to its conceptual framing, the mechanisms underlying location estimation are similar across development (Huttenlocher et al., 1991, 1994; Newcombe \& Huttenlocher, 2000). Thus, developmental differences in location estimation result from changes in the cues used to define spatial categories, not from changes in the underlying processes. For instance, young children use highly salient cues to define large spatial regions, and, with age, children focus on less obvious cues that can be used to define smaller, more precise regions (Huttenlocher et al., 1994). Tracking these changes in cues and the resulting stability and flexibility of responding is another future challenge for the CA model that has the potential to facilitate our understanding of cognitive development.

\section{The Dynamic Field Theory (DFT)}

Recently, Spencer, Simmering, Schutte, and Schöner (2007; Spencer, Smith, \& Thelen, 2001) outlined a second model of spatial memory-the DFT. According to the DFT, a population of neurons in working memory actively maintains location-related information over time because neighboring neurons influence one another through a local excitation/lateral inhibition interaction function. As such, an activated neuron excites neurons that code similar spatial locations and inhibits neurons that code more distant locations. If local excitation is strong and focused, dynamic fields enter a self-sustaining state in which activation is maintained even after the input is removed (Thelen et al., 2001). Activation in working memory leaves a trace of activation in long-term memory, which decays quite slowly. This activation, in turn, can serve as input to working memory. This reciprocal process can construct an experience-based category, leading to bias toward previously experienced locations and, indirectly, to overestimation across category boundaries.

As this discussion illustrates, the DFT outlines neurally plausible mechanisms that might underlie the maintenance of location information (e.g., stability) over multiple time scales. Moreover, recent extensions of the model focusing on changes in the precision of location coding over development might offer hints regarding why stability emerges prior to flexibility (Schutte et al., 2003; 
Spencer \& Schöner, 2003; Spencer et al., 2007). According to the spatial precision hypothesis, the function that governs excitatory and inhibitory interactions between neurons is broad and shallow during early development, leading to broad excitatory overlap among neurons that code similar locations and little inhibition of neurons that code divergent locations, which results in wide convergence of behavioral responding. The interaction function narrows and sharpens over development, so that neurons that code very similar locations greatly excite one another, and they inhibit neurons that code divergent locations. This narrower interaction function leads to more precise coding of locations, which could facilitate both increases in accuracy of coding individual locations and increased differentiation among divergent locations. It is possible that the increase in inhibition is critically important for the emergence of flexibility as responding shifts from one (stable) response pattern to another (stable) pattern (for related ideas concerning the importance of inhibition in flexibility, see Brace et al., 2006; Morton \& Munakata, 2002; Munakata, 1998). Current DFT modeling seeks to further specify the dynamics of responding over multiple time scales, offering details about the underlying mechanisms (e.g., Spencer et al., 2007). Can the DFT also explain the mechanisms underlying the integration of object and location information? Although a recent expansion of the DFT provides details regarding the incorporation of verbal choice information (Spencer, Simmering, \& Schutte, 2006; see also Spencer, Lipinski, \& Samuelson, in press), it is not clear how the model could account for the complexity of the present results, particularly the importance of object information. This represents a critical future challenge for the DFT.

In conclusion, the present findings reveal remarkable stability and developmental increases in flexibility of spatial organization based on object relatedness across childhood. As such, this investigation is one of the first to specify the emergence and balance of spatial category stability and flexibility over development, offering key details about the dynamics of cognitive processing. The present findings also highlight critical interactions between objects and locations, suggesting that category formation is a dynamic process that involves multiple cues and unfolds across real and developmental time scales. As such, the present investigation is one of many that will help the field move forward in addressing a key challenge: to understand the precise mechanisms underlying the complex dynamics of cognition.

\section{References}

Barsalou, L. W. (1983). Ad hoc categories. Memory \& Cognition, 11, 211-227.

Barsalou, L. W. (2003). Situated simulation in the human conceptual system. Language and Cognitive Processes, 18, 513-562.

Bauer, P. J. (2004). Getting explicit memory off the ground: Steps toward construction of a neuro-developmental account of changes in the first two years of life. Developmental Review, 24, 347-373.

Bauer, P. J. (2005). Developments in declarative memory: Decreasing susceptibility to storage failure over the second year of life. Psychological Science, 16, 41-47.

Blaye, A., \& Bonthoux, F. (2001). Thematic and taxonomic relations in preschoolers: The development of flexibility in categorization choices. British Journal of Developmental Psychology, 19, 395-412.

Brace, J. J., Morton, J. B., \& Munakata, Y. (2006). When actions speak louder than words: Improving children's flexibility in a card-sorting task. Psychological Science, 17, 665-669.
Bull, R., \& Scerif, G. (2001). Executive functioning as a predictor of children's mathematics ability: Inhibition, switching, and working memory. Developmental Neuropsychology, 19, 273-293.

Carlson, S. M. (2005). Developmentally sensitive measures of executive function in preschool children. Developmental Neuropsychology, 28, $595-616$.

Carlson-Radvansky, L. A., Covey, E. S., \& Lattanzi, K. M. (1999). "What" effects on "where": Functional influences on spatial relations. Psychological Science, 10, 516-521.

Carlson-Radvansky, L. A., \& Tang, Z. (2000). Functional influences on orienting a reference frame. Memory \& Cognition, 28, 812-820.

Cohen, R., Baldwin, L. M., \& Sherman, R. C. (1978). Cognitive maps of a naturalistic setting. Child Development, 49, 1216-1218.

Daniels, K., Toth, J., \& Jacoby, L. (2006). The aging of executive functions. In E. Bialystok \& F. I. M. Crick (Eds.), Lifespan cognition: Mechanisms of change (pp. 96-111). Oxford, England: Oxford University Press.

Deák, G. O. (2000). The growth of flexible problem solving: Preschool children use changing verbal cues to infer multiple word meanings. Journal of Cognition and Development, 1, 157-191.

Deák, G. O., Ray, S. D., \& Pick, A. D. (2004). Effects of age, reminders, and task difficulty on young children's rule-switching flexibility. Cognitive Development, 19, 385-400.

Diamond, A. (2006). The early development of executive function. In E. Bialystok \& F. I. M. Crick (Eds.), Lifespan cognition: Mechanisms of change (pp. 70-95). Oxford, England: Oxford University Press.

Diamond, A., \& Doar, B. (1989). The performance of human infants on a measure of frontal cortex function, the delayed response task. Developmental Psychobiology, 22, 271-294.

Engebretson, P. H., \& Huttenlocher, J. (1996). Bias in spatial location due to categorization: Comment on Tversky and Schiano. Journal of Experimental Psychology: General, 125, 96-108.

Goldstone, R. L. (1995). Effects of categorization on color perception. Psychological Science, 6, 298-304.

Hirtle, S. C., \& Kallman, H. J. (1988). Memory for the locations of pictures: Evidence for hierarchical clustering. American Journal of Psychology, 101, 159-170.

Hirtle, S. C., \& Mascolo, M. F. (1986). Effect of semantic clustering on the memory of spatial locations. Journal of Experimental Psychology: Learning, Memory, and Cognition, 12, 182-189.

Hughes, C. (1998). Executive function in preschoolers: Links with theory of mind and verbal ability. British Journal of Developmental Psychology, 16, 233-253.

Hund, A. M., \& Plumert, J. M. (2002). Delay-induced bias in children's memory for location. Child Development, 73, 829-840.

Hund, A. M., \& Plumert, J. M. (2003). Does information about what things are influence children's memory for where things are? Developmental Psychology, 39, 939-948.

Hund, A. M., \& Plumert, J. M. (2005). The stability and flexibility of spatial categories. Cognitive Psychology, 50, 1-44.

Hund, A. M., Plumert, J. M., \& Benney, C. J. (2002). Experiencing nearby locations together in time: The role of spatial and temporal contiguity in children's memory for location. Journal of Experimental Child Psychology, 82, 200-225.

Hund, A. M., \& Spencer, J. P. (2003). Developmental changes in the relative weighting of geometric and experience-dependent location cues. Journal of Cognition and Development, 4, 3-38.

Huttenlocher, J., Hedges, L. V., \& Duncan, S. (1991). Categories and particulars: Prototype effects in estimating spatial location. Psychological Review, 98, 352-376.

Huttenlocher, J., Hedges, L. V., \& Vevea, J. L. (2000). Why do categories affect stimulus judgments? Journal of Experimental Psychology: General, 129, 220-241. 
Huttenlocher, J., Newcombe, N., \& Sandberg, E. H. (1994). The coding of spatial location in young children. Cognitive Psychology, 27, 115-147.

Jones, S. B., \& Smith, L. B. (1993). The place of perception in children's concepts. Cognitive Development, 8, 113-139.

Kail, R. (1984). The development of memory in children. New York: Freeman

Kail, R. (2002). Developmental change in proactive interference. Child Development, 73, 1703-1714.

Kirkham, N. Z., Cruess, L., \& Diamond, A. (2003). Helping children apply their knowledge to their behavior on a dimension-switching task. Developmental Science, 6, 449-467.

Landau, B., Smith, L. B., \& Jones, S. S. (1988). The importance of shape in early lexical learning. Cognitive Development, 3, 299-321.

Madole, K. L., \& Oakes, L. M. (1999). Making sense of infant categorization: Stable processes and changing representations. Developmental Review, 19, 263-296.

Mandler, J. M. (1993). Commentary on concepts. Cognitive Development, $8,141-148$

Markman, A. B., \& Ross, B. H. (2003). Category use and category learning. Psychological Bulletin, 129, 592-613.

Mervis, C. B. (1985). On the existence of prelinguistic categories: A case study. Infant Behavior and Development, 8, 293-300.

Morton, J. B., \& Munakata, Y. (2002). Active versus latent representations: A neural network model of perseveration and dissociation in early childhood. Developmental Psychobiology, 40, 255-265.

Munakata, Y. (1998). Infant perseveration and implications for object permanence theories: A PDP model of the A-not-B task. Developmental Science, 1, 161-184.

Newcombe, N., \& Huttenlocher, J. (2000). Making space: The development of spatial representation and reasoning. Cambridge, MA: MIT Press.

Newcombe, N., \& Liben, L. S. (1982). Barrier effects in the cognitive maps of children and adults. Journal of Experimental Child Psychology, 34, $46-58$.

Oakes, L. M., \& Madole, K. L. (2000). The future of infant categorization research: A process-oriented approach. Child Development, 71, 119126

Oakes, L. M., Plumert, J. M., Lansink, J. M., \& Merryman, J. D. (1996). Evidence for task-depended categorization in infancy. Infant Behavior and Development, 19, 425-440.

Oakes, L. M., Ross-Sheehy, S., \& Luck, S. J. (2006). Rapid development of feature binding in visual short-term memory. Psychological Science, 17, 781-787.

Pennington, B. F., \& Ozonoff, S. (1996). Executive functions and developmental psychopathology. Journal of Child Psychology and Psychiatry and Allied Disciplines, 37, 51-87.

Plumert, J. M. (1994). Flexibility in children's use of spatial and categorical organizational strategies in recall. Developmental Psychology, 30, $738-747$.

Plumert, J. M., \& Hund, A. M. (2001). The development of memory for location: What role do spatial prototypes play? Child Development, 72 , 370-384.

Plumert, J. M., Hund, A. M., \& Recker, K. M. (2007). Organismenvironment interaction in spatial development: Explaining categorical bias in memory for location. In J. M. Plumert \& J. P. Spencer (Eds.), The emerging spatial mind (pp. 25-52). Oxford, England: Oxford University Press.

Postma, A., Kessels, R. P. C., \& van Asselen, M. (2004). The neuropsychology of object-location memory. In G. L. Allen (Ed.), Human spatial memory: Remembering where (pp. 143-160). Mahwah, NJ: Erlbaum.

Rose, S. A. (1981). Developmental changes in infants' retention of visual stimuli. Child Development, 52, 227-233.

Rose, S. A., Feldman, J. F., \& Jankowski, J. J. (2003). Infant visual recognition memory: Independent contributions of speed and attention. Developmental Psychology, 39, 563-571.

Ross, B. H. (1996). Category representations and the effects of interacting with instances. Journal of Experimental Psychology: Learning, Memory, and Cognition, 22, 1249-1265.

Samuelson, L. K., \& Smith, L. B. (2000). Children's attention to rigid and deformable shape in naming and non-naming tasks. Child Development, $71,1555-1570$

Sandberg, E. H., Huttenlocher, J., \& Newcombe, N. (1996). The development of hierarchical representation of two-dimensional space. Child Development, 67, 721-739.

Schutte, A. R., \& Spencer, J. P. (2002). Generalizing the dynamic field theory of the A-not-B error beyond infancy: Three-year-olds' delay- and experience-dependent location memory biases. Child Development, 73, 377-404.

Schutte, A. R., Spencer, J. P., \& Schöner, G. (2003). Testing the dynamic field theory: Working memory for locations becomes more spatially precise over development. Child Development, 74, 1393-1417.

Schyns, P. G., \& Murphy, G. L. (1994). The ontogeny of part representation in object concepts. In D. L. Medin (Ed.), The psychology of learning and motivation (Vol. 31, pp. 305-349). New York: Academic Press.

Schyns, P. G., \& Rodet, L. (1997). Categorization creates functional features. Journal of Experimental Psychology: Learning, Memory, and Cognition, 23, 681-696.

Shelton, A. L., \& McNamara, T. P. (2004). Orientation and perspective dependence in route and survey learning. Journal of Experimental Psychology: Learning, Memory, and Cognition, 30, 158-170.

Smith, L. B. (2000). From knowledge to knowing: Real progress in the study of infant categorization. Infancy, 1, 91-97.

Smith, L. B., \& Heise, D. (1992). Perceptual similarity and conceptual structure. In B. Burns (Ed.), Percepts, concepts, and categories: The representation and processing of information (Vol. 93, pp. 233-272). New York: North Holland.

Smith, L. B., \& Samuelson, L. K. (1997). Perceiving and remembering: Category stability, variability, and development. In K. Lamberts \& D. Shanks (Eds.), Knowledge, concepts, and categories (pp. 161-195). East Sussex, England: Psychology Press.

Spencer, J. P., \& Hund, A. M. (2002). Prototypes and particulars: Geometric and experience-dependent spatial categories. Journal of Experimental Psychology: General, 131, 16-37.

Spencer, J. P., \& Hund, A. M. (2003). Developmental continuity in the processes that underlie spatial recall. Cognitive Psychology, 47, 432480 .

Spencer, J. P., Lipinski, J., \& Samuelson, L. K. (in press). It's in the eye of the beholder: Spatial language and spatial memory use the same perceptual reference frames. In L. B. Smith, M. Gasser, \& K. Mix (Eds.), The spatial foundations of language. Oxford, England: Oxford University Press.

Spencer, J. P., \& Schöner, G. (2003). Bridging the representational gap in the dynamical systems approach to development. Developmental Science, 6, 392-412.

Spencer, J. P., Simmering, V. R., \& Schutte, A. R. (2006). Toward a formal theory of flexible spatial behavior: Geometric category biases generalize across pointing and verbal response types. Journal of Experimental Psychology: Human Perception and Performance, 32, 473-490.

Spencer, J. P., Simmering, V. R., Schutte, A. R., \& Schöner, G. (2007). What does theoretical neuroscience have to offer the study of behavioral development? Insights from a dynamic field theory of spatial cognition. In J. M. Plumert \& J. P. Spencer (Eds.), The emerging spatial mind (pp. 320-361). Oxford, England: Oxford University Press.

Spencer, J. P., Smith, L. B., \& Thelen, E. (2001). Tests of a dynamic systems account of the A-not-B error: The influence of prior experience on the spatial memory abilities of two-year-olds. Child Development, 72 , 1327-1346. 
Thelen, E., Schöner, G., Scheier, C., \& Smith, L. B. (2001). The dynamics of embodiment: A dynamic field theory of infant perseverative reaching errors. Behavioral and Brain Sciences, 24, 1-86.

Thelen, E., \& Smith, L. B. (1994). A dynamic systems approach to the development of cognition and action. Cambridge, MA: MIT Press.

Tversky, A. (1977). Features of similarity. Psychological Review, 84, 327-352.

Ungerleider, L. G., \& Mishkin, M. (1982). Two cortical visual systems. In D. J. Ingle, M. A. Goodale, \& R. J. W. Mansfield (Eds.), Analysis of visual behavior (pp. 549-586). Cambridge, MA: MIT Press.

Uttal, D. H. (1994). Preschoolers' and adults' scale translation and reconstruction of spatial information acquired from maps. British Journal of Developmental Psychology, 12, 259-275.

Uttal, D. H. (1996). Angles and distances: Children's and adults' reconstruction and scaling of spatial configurations. Child Development, 67, 2763-2779.

Uttal, D. H., Gregg, V. H., Tan, L. S., Chamberlin, M. H., \& Sines, A. (2001). Connecting the dots: Children's use of a systematic figure to facilitate mapping and search. Developmental Psychology, 37, 338-350.
Welsh, M. C., Pennington, B. F., \& Groisser, D. B. (1991). A normative-developmental study of executive function: A window of prefrontal function in children. Developmental Neuropsychology, 7 , 131-149.

Yerys, B. E., \& Munakata, Y. (2006). When labels hurt but novelty helps: Children's perseveration and flexibility in a card-sorting task. Child Development, 77, 1589-1607.

Zelazo, P. D., Carter, A., Reznick, J. S., \& Frye, D. (1997). Early development of executive function: A problem-solving framework. Review of General Psychology, 1, 1-29.

Zelazo, P. D., Frye, D., \& Rapus, T. (1996). An age-related dissociation between knowing rules and using them. Cognitive Development, 11, $37-63$.

Received May 26, 2006

Revision received July 10, 2007 Accepted September 5, 2007

\section{Correction to Duncan et al. (2007)}

In the article, "School Readiness and Later Achievement," by Greg J. Duncan, Chantelle J. Dowsett, Amy Claessens, Katherine Magnuson, Aletha C. Huston, Pamela Klebanov, Linda S. Pagani, Leon Feinstein, Mimi Engel, Jeanne Brooks-Gunn, Holly Sexton, Kathryn Duckworth, and Crista Japel (Developmental Psychology, 2007, Vol. 43, No. 6, p. 1428), the DOI for the supplemental materials was printed incorrectly. The correct DOI is as follows: http://dx.doi.org/10. 1037/0012-1649.43.6.1428.supp

DOI: $10.1037 / 0012-1649.44 .1 .217$ 